\title{
ERRATUM
}

\section{Erratum to: Characterizing metalloendonuclease mixed metal complexes by global kinetic analysis}

\author{
Charulata B. Prasannan • Fuqian Xie • \\ Cynthia M. Dupureur
}

Published online: 14 September 2010

(C) SBIC 2010

\section{Erratum to: J Biol Inorg Chem (2010)15:533-545 \\ DOI 10.1007/s00775-010-0621-6}

Unfortunately an erroneous version of Fig. 7 had been used in the original publication. The correct version of the figure is given below:

Fig. 7 Summary of fits and simulations for model III (all mixed species inactive). a Sample progress curves: circles data points for $10 \mathrm{mM} \mathrm{Mg}(\mathrm{II})$, line prediction of experimental curve using parameters determined from the fit. Squares data points for $5 \mathrm{mM} \mathrm{Mg}(\mathrm{II}) / 250 \equiv \mathrm{M}$ $\mathrm{Ca}(\mathrm{II})$, dash prediction of experimental curve using parameters determined from the fit. Triangles data points for $5 \mathrm{mM} \mathrm{Mg}$ (II)/ $1 \mathrm{mM} \mathrm{Ca}(\mathrm{II})$, dots prediction of experimental curve using parameters determined from the fit. b-d Comparison of experimental (closed squares) and predicted kobs (open circles) for the indicated conditions

The online version of the original article can be found under doi:10.1007/s00775-010-0621-6.

C. B. Prasannan · F. Xie · C. M. Dupureur $(\bowtie)$

Department of Chemistry and Biochemistry,

Center for Nanoscience,

University of Missouri St. Louis,

St. Louis, MO 63121, USA

e-mail: cdup@umsl.edu
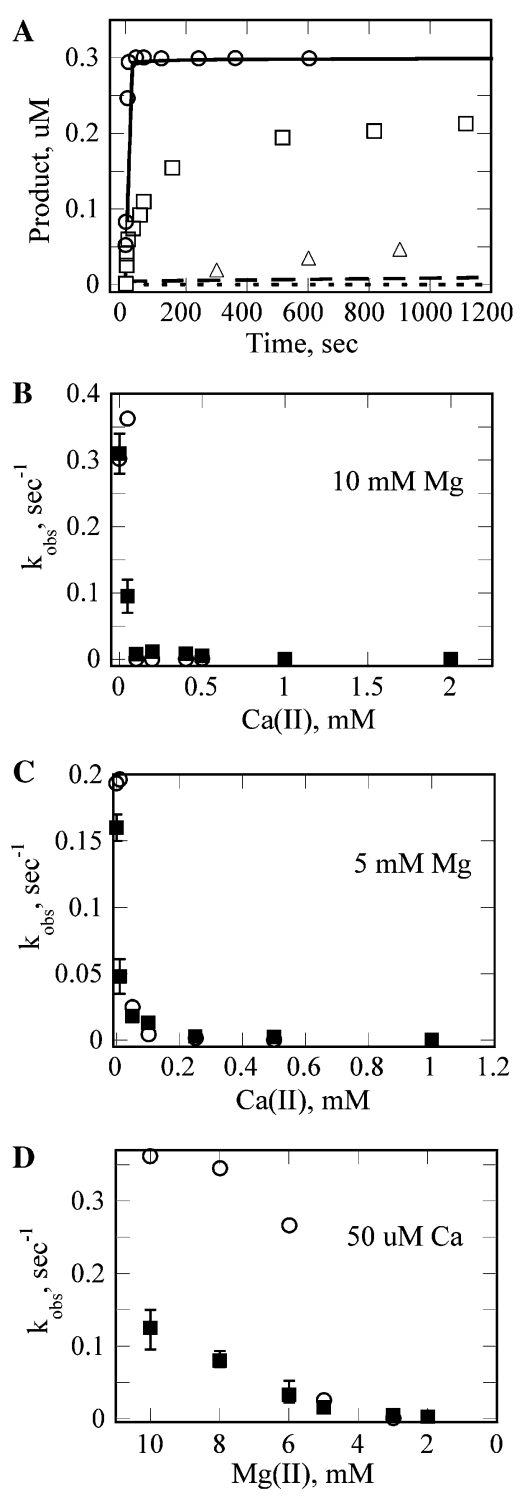